\title{
Comparing Contact Calling Between Black Tufted-Ear Marmosets (Callithrix penicillata) in a Noisy Urban Environment and in a Quiet Forest
}

\author{
S. G. Santos1 \& M. H. L. Duarte1,2 \& R. S. Sousa-Lima3 \& R. J. Young4
}

\author{
1 Laboratory of Bioacoustics, Museum of Natural Sciences, Pontifical Catholic University of Minas \\ Gerais, Belo Horizonte, Minas Gerais 30535-901, Brazil \\ ${ }_{2}$ Graduate Program of Vertebrate Biology, Pontifical Catholic University of Minas Gerais, Belo \\ Horizonte, Minas Gerais 30535-901, Brazil \\ 3 Laboratory of Bioacoustics, Federal University of Rio Grande do Norte, Natal 59078-970, Brazil \\ 4 School of Environment and Life Sciences, University of Salford, Manchester M5 4WT, UK
}

\begin{abstract}
All habitats have some level of noise but anthropogenic sounds such as those produced by traffic are structurally different from natural sounds, and could cause organisms living in noisy urban areas to modify their vocal communication. We compared temporal and spectral parameters of contact calls in black tufted-ear marmosets (Callithrix penicillata) living in a noisy and a quiet area. From February 2009 to March 2012 we recorded spontaneously produced phee vocalizations by marmosets in two areas in Minas Gerais, Brazil: a noisy urban park $(\mathrm{N}=581)$ in Belo Horizonte, and a quiet natural forest, on Cauaia farm in Matozinhos city $(\mathrm{N}=560)$. We measured the duration, frequencies, and rate of phee vocalizations. We found that marmosets' phee vocalizations were significantly longer in the noisy area than in the quiet area. The low, high, and dominant frequencies were significantly lower in the noisy area than in the quiet area, and contact calling was less frequent in the noisy area than in the quiet area. We suggest that the differences between marmoset contact calls from noisy and quiet areas are influenced by anthropogenic noise.
\end{abstract}

Keywords Noise . Primates . Vocal communication

\section{Introduction}

Anthropogenic noise is a critical pollution problem for wildlife owing to its adverse effects on animal behavior and physiology (Duarte et al. 2015; Kight and Swaddle 2011; Popper and Hastings 2009; Warren et al. 2006). Like chemical pollution, noise pollution usually increases with increasing human population density (Katti andWarren 2004). All habitats are noisy, but the acoustic characteristics of sounds produced by traffic (cars, motorcycles, trains, and aircraft), buildings, and industries are different from most sounds in natural habitats, in terms of their dominant frequencies, rise time, duty cycle, and impulsiveness (Brumm 2006). In humans, noise causes physiological problems such as hearing loss, increased stress hormone levels, and hypertension (Babisch 2003; Jarup et al. 2008; Ryals et al. 1999).

The effect of noise has been a concern for marine mammals that rely heavily on sound communication since the 1990s (Richardson et al. 1995) and for terrestrial fauna more recently (Slabbekoorn and Peet 2003). Studies in urban areas show that noise pollution is a serious threat for terrestrial animals (Halfwerk et al. 2011; Rabin et al. 2003; Slabbekoorn and Ripmeester 2008). High levels of noise can mask acoustic signals, hindering territorial defense, mate attraction, and other important social interactions (Brumm et al. 2004). Beside this, noise can distract animals, making them more vulnerable to predation (Chan et al. 2010) and can cause stress, with negative effects on physiology and development (Kight and Swaddle 2011). Animals may use several mechanisms to mitigate the effects of noise, for example, by altering their vocalizations by increasing the amplitude, i.e., the Lombard effect; changing the frequency (Slabbekoorn and Peet 2003), duration, or number of notes (Sun and Narins 2005; Warren et al. 2006); and changing the timing of vocal activity (Bergen and Abs 1997; Sousa-Lima and Clark 2008). 
There are several examples of vocal plasticity in primates. The vocal structure of individuals can change as a result of social interactions (Janik and Slater 2000), changes in social status or ecological niche (Snowdon 2009), and changes in the environment (Brumm 2004). An increase in background noise amplitude was associated with a significant increase in call amplitude and syllable duration in cotton-top tamarins (Saguinus Oedipus: Egnor and Hauser 2006). Changes in the design of a signal may have short- or long-term or even evolutionary consequences on the communication system of animals via natural or sexual selection (Warren et al. 2006). Studies of the effects of noise on primates' vocalizations are important to develop management and conservation strategies in natural areas close to anthropogenic activities (Brumm 2004; Duarte et al. 2011; Hotchkin et al. 2015).

The black tufted-ear marmoset (Callithrix penicillata) is an endemic species from Brazil that occurs in Cerrado, Caatinga, and Atlantic Forest (Miranda and Faria 2001). Human encroachment on natural areas has induced occupation of urban areas by this species (Chagas et al. 1999). Owing to their behavioral flexibility, marmosets can adapt to changing environmental conditions and, to some degree, to human influence (Stevenson and Rylands 1988). Wild common marmosets (C. jacchus) possess 13 different call types: trill, twitter, tsik, tsê, egg, chatter, squeal, moaning, very brief whistle, alarm 1 and 2; scream, and phee calls (Bezerra and Souto 2008). Phee calls are

single- or multiphrase contact calls, which are frequently emitted by wild marmosets of both species (C. jacchus and C. penicillata) in the same context. These calls are long and tonal with durations of $0.5-2 \mathrm{~s}$ and fundamental frequencies varying from 6 to $10 \mathrm{kHz}$ (Roy et al. 2011). Phee calls are long-distance vocalizations and can have both intra- and intergroup functions in Neotropical primates such as mate attraction, defense, and territorial behavior (Norcross and Newman 1993; Oliveira and Ades 2004). We tested the hypothesis that noise influences marmoset calls. We predicted that the rate and structure of the marmosets' phee vocalization would differ between a noisy urban area and a forested quiet area.

\section{Methods}

\section{Study Area}

We conducted the study from February 2009 to March 2012 in two areas in Minas Gerais, Brazil: 1) noisy: an urban park (Municipal Park, Belo Horizonte) and 2) quiet: a natural forest fragment on a farm in Matozinhos Municipality, where human presence is rare. The noisy site is surrounded by major city avenues, a soundscape that differs markedly from nature, mainly owing to excessive traffic noise sounds, park visitors, and a fair every Sunday (Duarte et al. 2011). The equivalent noise levels (a logarithmic mean of noise levels at 20-min intervals) at the Municipal Park range from 50.1 to 80.0 $\mathrm{dB}$ on weekdays and from 50.1 to $74.0 \mathrm{~dB}$ on weekends (Duarte et al. 2011). The quiet site is 600 acres of semideciduous forest, which is a private reserve, and is probably the largest natural forest fragment in the region. Noise levels in the Quiet area ranged from $30.1 \mathrm{~dB}$ to $37.2 \mathrm{~dB}$.

\section{Study Subjects}

We studied the only group of marmosets living in the Municipal Park. The number of individuals ranged from 8 to 11 during the study owing to births and deaths. We recorded vocalizations from three different groups in the quiet area. The number of individuals ranged from 6 to 13 in group 1, 8 to 11 in group 2 , and 9 to 13 in group 3 .

\section{Data Collection}

We searched for the marmosets and recorded their spontaneous vocalizations when we found them using a Marantz Professional Solid State Recorder (Model PMD660) and a shotgun microphone (SennheiserME66). We also recorded the name of the individual and the calling context after each vocalization sequence.We did not play any stimuli to 
the marmosets to elicit call responses.

Data Analyses

We extracted the duration and low, high, and dominant frequency measurements of each call from phee vocalizations using the program Raven Pro 1.5 (Bioacoustics Research Program, Cornell Lab of Ornithology). We extracted all the measurements

from the fundamental frequency because the literature indicates that this band is most modified by urban noise (Slabbekoorn and Peet 2003).

We used only the phee vocalizations for analyses, since other calls were difficult to record from a distance. We compared the mean number of phee calls per hour and the acoustic parameters of marmoset vocalizations from noisy and quiet areas using MannWhitney test in Minitab version 15.

\section{Ethical Note}

The study reported in this paper complies with all appropriate laws in Brazil in relation to the treatment of animals. The authors have no conflicts of interest to report

\section{Results}

We recorded 560 phee calls in the quiet area and 581 in the noisy area (Fig. 1).

Marmosets' phee vocalizations were significantly longer in the noisy area than in the quiet area $(\mathrm{U}=118495.5, \mathrm{P}<0.001)$ (Fig. 2). The low, high, and dominant fundamental frequencies of phee vocalizations were significantly higher in the quiet area than in the noisy area (Low $\mathrm{U}=110,118.5, \mathrm{P}<0.001$; High $\mathrm{U}=102,614.5, \mathrm{P}<0.001$, Dominant $U=95,000, \mathrm{P}<0.001$ ) (Fig. 2). Marmosets called more often in the quiet $(84 \pm 43 \mathrm{calls} / \mathrm{h})$ than in the noisy area $(17.1 \pm 29.9 \mathrm{calls} / \mathrm{h})(\mathrm{U}=12,000 ; \mathrm{P}<0.001)$.

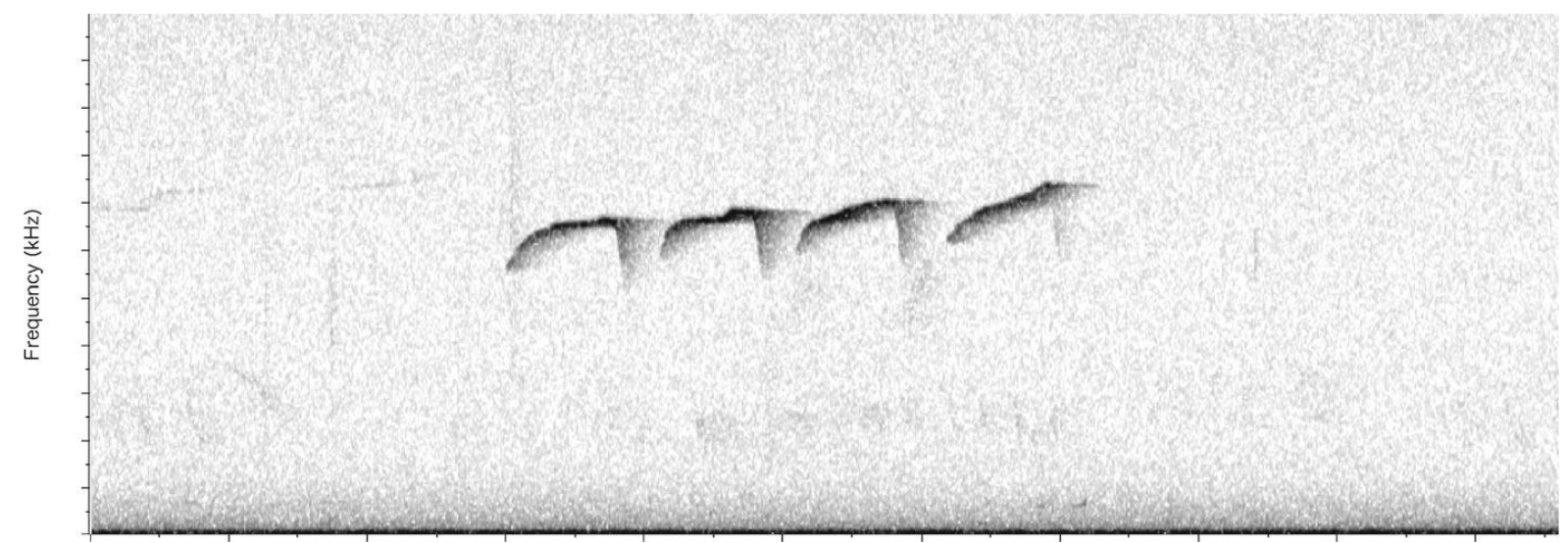

Fig. 1 Phee vocalizations selected from focal marmosets (Callithrix penicillata) recorded in the quiet forest area (Cauaia farm, Matozinhos, Minas Gerais, Brazil). 
Duration

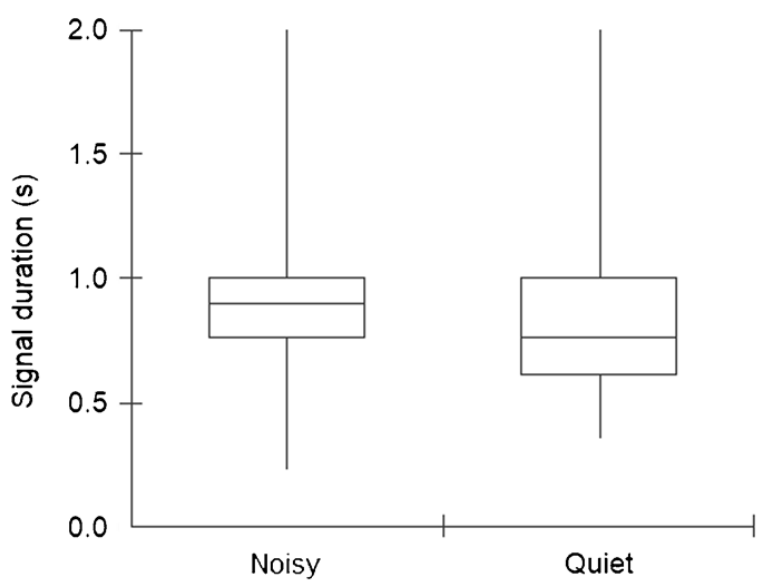

High frequency

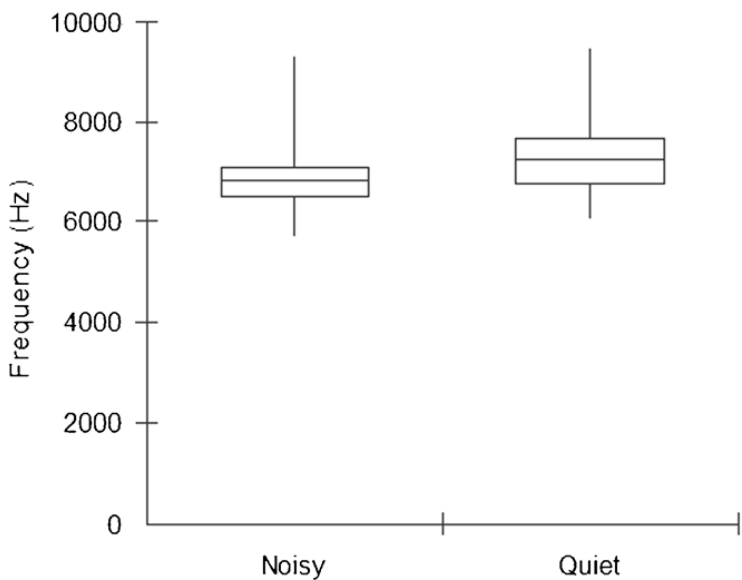

Low frequency

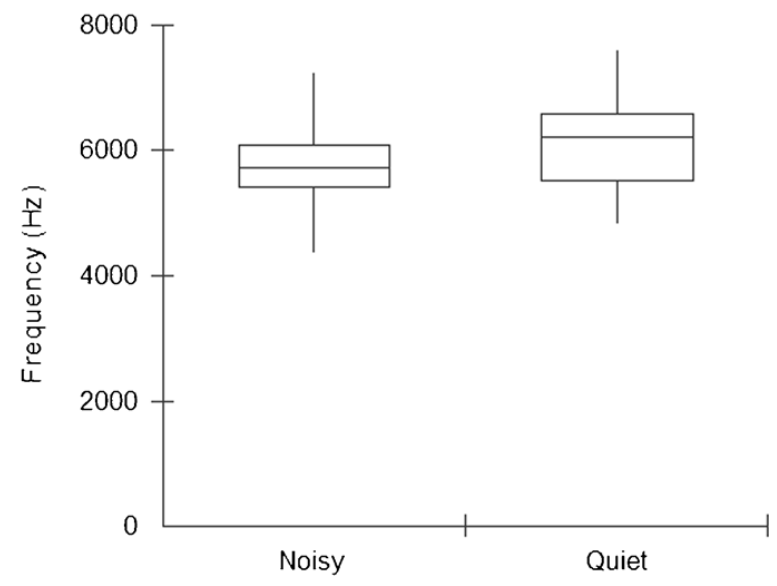

Dominant frequency

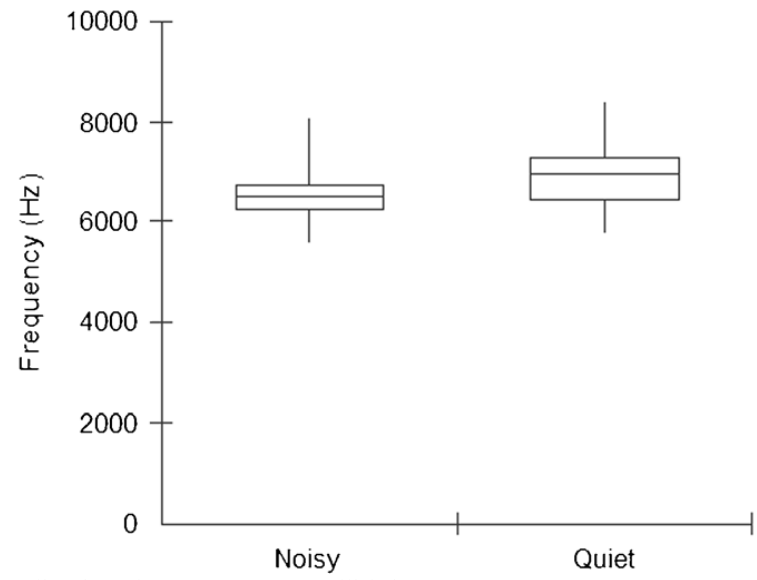

Fig. 2 Median and interquartile ranges of acoustic parameters of phee vocalizations by marmosets (Callithrix penicillata) in a noisy (Municipal Park, Belo Horizonte, Minas Gerais, $\mathrm{N}=581$ ) and a quiet (Cauaia farm, Matozinhos, Minas Gerais, N = 560) environment in Brazil.

\section{Discussion}

We found differences in the temporal and spectral characteristics and rate of marmoset phee vocalizations between quiet and noisy environments. We cannot rule out group differences in vocalizations due to our study design, and our data are pseudo-replicated owing to multiple measures of calls by the same individuals. Nevertheless, we found that marmoset calls were longer in a noisy than in a quiet environment, that fundamental frequencies differed between the two environments, and that contact calling was less frequent in the noisy environment than in the quiet environment.

Our finding that marmoset calls were longer in a noisy urban environment than in a quiet environment reflects other studies in which primates' brief vocalizations are longer in noisy environments than in quiet environments (Brumm et al. 2004; Egnor and Hauser 2006). The difference in mean call duration in our study was significant but very small (140 ms). Nevertheless, marmosets may be able to detect this difference because temporal resolution in mammals has a single time integration constant of $8 \mathrm{~ms}$ (reviewed in Fay and Popper 1994). Therefore, an increase in sound duration on the order of $140 \mathrm{~ms}$ could increase call detection and recognition of the signals by marmosets in a noisy area. Psychoacoustic studies would help to understand whether black-tufted marmosets can discriminate the differences in spectral variables. 
Our finding that marmosets called at lower low, high, and dominant frequencies in the noisy area than in the quiet area contrasts, with the most common finding in birds (Slabbekoorn and Peet 2003) and cetaceans (Parks et al. 2007), where low-frequency values are higher in the presence of noise, minimizing the overlap between the calls and anthropogenic sounds, i.e., reducing masking. Higher frequencies are less efficient than lower frequencies over longer distances (Wiley and Richards 1978), and human disturbance can change the way in which acoustic signals are transmitted (Rabin et al. 2003). We suggest that the marmosets decrease the frequency of contact calls to improve their communication range, since the location of the sender is important in contact calling.

The number of calls per hour was lower in the noisy area than in the quiet area, suggesting that marmosets do not invest as much in contact calling in an environment in which calls are often masked by noise and less likely to be detected. Our findings reflect those for pygmy marmosets (Cebuella pygmaea), which vocalize less in areas with human activity (de la Torre et al. 2000). An alternative explanation is that the absence of conspecific groups in the noisy area may have affected the amount of intergroup contact calling. However, this is unlikely to influence intragroup contact calling, suggesting that the effect of noise may explain reduced calling rates in the noisy area.

Belo Horizonte Municipal Park is located at the heart of the city's transportation hub. According to the mayor's office of Belo Horizonte, the city has 2874 buses, which transport 1.5 million people per day.We identified bus braking sounds in the recordings that sounded like phee calls and have low fundamental frequencies similar to those of the marmosets' phee calls in the noisy area. The overlap between the lower frequency of phee calls and buses braking sounds may confuse the marmosets and cause them to call less or change their call frequency.

Recent studies propose that birds could achieve higher signal-to-noise ratios more efficiently by elevating amplitude rather than the frequency when exposed to lowfrequency noise (Nemeth and Brumm 2010). We did not calculate amplitude because we could not measure distance to the vocalizing individual with confidence. However, cotton-top tamarins (Saguinus oedipus) alter the amplitude of their vocalizations when subjected to intense noise background, i.e., the Lombard effect (Egnor and Hauser 2006), and the same may have occurred in our study individuals.

Our results show that, although marmosets can inhabit urban environments, noise in those areas may influence their communication. Together with a study showing that marmosets prefer quieter areas in the park than louder areas (Duarte et al. 2011), they illuminate primate response to noise pollution. Differences in communication patterns are indicators of human influence on animals and it is important to evaluate them when making decisions about conservation strategies in urban areas.

\section{Data Availability}

The datasets analyzed during the study are availabe from the corresponding author on reasonable request.

Acknowledgments The authors thank all of the staff at the Municipal Park of Belo Horizonte and Cauaia farm. We are also grateful to Danusa Guedes for her help during data acquisition and the editor and anonymous referees for their useful comments and suggestions on this manuscript. We also thank the Programa de Educação Tutorial (MEC/SESu), for encouraging research and for financial support of S. G Santos. M. H. L. Duarte and S. G. Santos were also supported by the Fundação de Amparo à Pesquisa de Minas Gerais (FAPEMIG), VALE S.A and CAPES postgraduate and post doc scholarships. R. J. Young and R. S. Sousa-Lima received financial support from FAPEMIG and Conselho Nacional de Pesquisa (CNPq).

\section{References}

Babisch,W. (2003). Stress hormones in the research on cardiovascular effects of noise. Noise \& Health, 5 , $1-11$. 
Bergen, F., \& Abs, M. (1997). Etho-ecological study of the singing activity of the blue tit (Parus caeruleus), great tit (Parus major) and chaffinch (Fringilla coelebs). Journal für Ornithologie, 138, 451-467.

Bezerra, B. M., \& Souto, A. (2008). Structure and usage of the vocal repertoire of Callithrix jacchus. International Journal of Primatology, 29, 671.

Brumm, H. (2004). The impact of environmental noise on song amplitude in a territorial bird. Journal of Animal Ecology, 73, 434-440.

Brumm, H. (2006). Signaling through acoustic windows: Nightingales avoid interspecific competition by short-term adjustment of song timing. Journal of Comparative Physiology, 12, 1279-1285.

Brumm, H., Voss, K., Köllmer, I., \& Todt, D. (2004). Acoustic communication in noise: Regulation of call characteristics in a New World monkey. The Journal of Experimental Biology, 207, 443-448.

Chagas, A. C. S., Piemonte, D. V., \& Raposo Filho, J. R. (1999). Observations on the behaviour of the Callithrix penicillata (Geoffroy, 1912) (Callitrichidae: Primates) in Santa Candida Biological Reserve, Juiz de Fora, Minas. Bioscience Journal, 15, 25-33.

Chan, A. A. Y.-H., Giraldo-Perez, P., Smith, S., \& Blumstein, D. T. (2010). Anthropogenic noise affects risk assessment and attention: the distracted prey hypothesis. Biology Letters, 6, 458-461.

de la Torre, S., Snowdon, C. T., \& Bejarano,M. (2000). Effects of human activities on wild pygmy marmosets in Ecuadorian Amazonia. Biological Conservation, 94, 153-163.

Duarte, M. H. L., Sousa-Lima, R. S., Young, R. J., Farina, A., Vasconcelos, M., et al (2015). The impact of noise from open-cast mining on Atlantic forest biophony. Biological Conservation, 191, 623-631.

Duarte, M. H. L., Vecci, M. A., Hirsch, A., \& Young, R. J. (2011). Noisy human neighbours affect where urban monkeys live. Biology Letters, 7, 840-842.

Egnor, S. E. R., \& Hauser, M. D. (2006). Noise-induced vocal modulation in cotton-top tamarins (Saguinus oedipus). American Journal of Primatology, 68, 1183-1190.

Fay, R. R., \& Popper, A. N., eds. (1994). Comparative hearing: Mammals. Springer Handbook of Auditory Research, Vol. 4, New York: Springer-Verlag.

Halfwerk, W., Holleman, L. J. M., Lessells, C. K. M., \& Slabbekoorn, H. (2011). Negative impact of traffic noise on avian reproductive success: Traffic noise and avian reproductive success. Journal of Applied Ecology, 48, 210-219.

Hotchkin, C. F., Parks, S. E., \& Weiss, D. J. (2015). Noise-induced frequency modifications of tamarin vocalizations: Implications for noise compensation in nonhuman primates. Plos ONE, 10(6), e0130211. Janik, V., \& Slater, P. J. B. (2000). The different roles of social learning in vocal communication. Animal Behavior, 60, 1-11.

Jarup, L., Babisch, W., Houthuijs, D., Pershagen, G., Katsouyanni, K., et al (2008). Hypertension and exposure to noise near airports: The hyena study. Environmental Health Perspectives, 116, 329-333. Katti, M., \& Warren, P. S. (2004). Tits, noise and urban bioacoustics. Trends in Ecology and Evolution, 19, 109-110.

Kight, C. R., \& Swaddle, J. P. (2011). How and why environmental noise impacts animals—an integrative, mechanistic review: Environmental noise and animals. Ecology Letters, 14, 1052-1061.

Miranda, G. H. B., \& Faria, D. S. (2001). Ecological aspects of black pincelled marmoset (Callithrix penicillata) in the cerradão and dense cerrado of the Brazilian central plateau. Brazilian Journal of Biology, 61, 397-404.

Nemeth, E., \& Brumm, H. (2010). Blackbirds sing higher-pitched songs in cities: Adaptation to habitat acoustics or side-effect of urbanization? Animal Behaviour, 78, 637-641.

Norcross, J. L., \& Newman, J. D. (1993). Context and gender specific difference in the acoustic structure of common marmoset (Callithrix jacchus) phee calls. American Journal of Primatology, 30, 37-54.

Oliveira, D. A. G., \& Ades, C. (2004). Long distance calls in neotropical primates. Anais da Academia Brasileira de Ciências, 76, 393-398.

Parks, E. S., Clark, C.W., \& Tyack, P. L. (2007). Short-and long-term changes in right whale calling behavior: The potential effects of noise on acoustic communication. Journal of the Acoustical Society of America, 122, 3725-3731.

Popper, A. N., \& Hastings, M. C. (2009). The effects on fish of human-generated (anthropogenic) sound. Integrative Zoology, 4, 43-52.

Rabin, L. A., Mc Cowan, B., Hooper, S. L., \& Owings, D. H. (2003). Anthropogenic noise and its effect on animal communication: An interface between comparative psychology and conservation biology. International Journal of Comparative Psychology, 16, 172-192.

Richardson,W. J., Greene Jr., C. R., Malme, C. I., \& Thomson, D. H. (1995).Marine mammals and noise. San Diego: Academic.

Roy, S.,Miller, C. T., Gottsch, D., \&Wang, X. (2011). Vocal control by the common marmoset in the presence of interfering noise. Journal of Experimental Biology, 214, 3619-3629.

Ryals, B. M., Dooling, R. J., \& Westbrook, E. (1999). Avian species differences in susceptibility to noise exposure. Hearing Research, 131, 71-88.

Slabbekoorn, H., \& Peet, M. (2003). Birds sing at a higher pitch in urban noise. Nature, 424, 267.

Slabbekoorn, H., \& Ripmeester, E. A. (2008). Birdsong and anthropogenic noise: Implications and applications for conservation. Molecular Ecology, 17, 72-83.

Snowdon, C. T. (2009). Plasticity of communication in nohuman primates. In M. Naguib, V. Janik, N.

Clayton, \& K. Zuberbuhler (Eds.), Advances in the study of behavior: Animal vocalization. San Diego: Academic.

Sousa-Lima, R., \& Clark, C. (2008). Modeling the effect of boat traffic on the fluctuation of humpback whale singing activity in the Abrolhos National Park, Brazil. Canadian Acoustics, 36, 174-181.

Stevenson, M. F., \& Rylands, A. B. (1988). The marmosets, genus Callithrix. In R. A. Mittermeier, A. B. Rylands, A. Coimbra-Filho, \& G. A. B. Fonseca (Eds.), Ecology and behavior of Neotropical primates (pp. 131-222). Contagem: Littera Maciel.

Sun, J. W. C., \& Narins, P. M. (2005). Anthropogenic sounds differentially affect amphibian call rate. Biological Conservation, 121, 419-427. 
Warren, P. S., Katti, M., Ermann, M., \& Brazel, A. (2006). Urban bioacoustics: It's not just noise. Animal Behaviour, 71, 491-502.

Wiley, R. H., \& Richards, D. G. (1978). Physical constraints on acoustic communication in the atmosphere: Implications for the evolution of animal vocalizations. Behavioral Ecology and Sociobiology, 3, 69. 